\title{
The Paradoxes of Revenge in Conflicts*
}

\author{
J. Atsu Amegashie** \\ Department of Economics \\ University of Guelph \\ Guelph, Ontario \\ Canada N1G 2W1 \\ jamegash@uoguelph.ca \\ Marco Runkel \\ Department of Economics \\ University of Munich \\ Ludwigstr. 28, Vgb., III \\ D-80539 Munich \\ Germany
}

marco.runkel@1rz.uni-muenchen.de

March 11, 2008

\begin{abstract}
We consider a differential game of a conflict between two factions who both have a desire to exact revenge. We show that, in contrast to conventional wisdom, the desire for revenge need not lead to escalation of conflicts. Surprisingly, in the open-loop equilibrium, the weaker faction exerts a higher effort when the stronger faction's military capability increases. This result is not possible in the absence of a desire for revenge. The closed-loop equilibrium is characterized by a self-deterrence effect: Anticipating the future retaliation of the opponent, a faction has an incentive to exert lower effort today. This strengthens the tendency to a stable steady state and paradoxically may decrease the factions' effort below the levels exerted in the case without revenge. We discuss some applications of our results and also offer an explanation of a puzzling empirical result obtained by Jaeger and Paserman (2007) in their study of the Israeli-Palestinian conflict. We also discuss the implications of revenge-dependent preferences for welfare economics and their strategic value as commitment devices.
\end{abstract}

Keywords: conflict, commitment, differential game, revenge. JEL Classification numbers: D74.

**Corresponding author: phone: 519-824-4120, fax: 519-763-8497.

*We thank Kjell Hausken, Zane Spindler, and especially Franz Wirl for helpful comments. We also thank Henry Thille for useful discussions. This research is funded by the Social Sciences and Humanities Research Council of Canada (SSHRC). This paper was previously titled "The desire for revenge and the dynamics of conflict." 
If it will feed nothing else, it will feed my revenge. - William Shakespeare, The Merchant of Venice (Shylock act III)

Revenge is profitable. - Edward Gibbon, Decline and Fall of the Roman Empire (ch. XI)

\section{Introduction}

The desire for revenge appears to be a common human trait. As Elster (1990, p. 862)

observes " $[R]$ evenge - the attempt, at some cost or risk to oneself, to impose suffering upon those who have made one suffer, because they made one suffer - is a universal phenomenon." Knutson (2004) found that the striatum, a key subcortical brain structure involved in feeling satisfaction, was activated in human volunteers subjected to PET imaging as they played a game designed to elicit acts of revenge. Moreover, in preindustrial societies, revenge was seen as an integral part of justice and retribution. This still persists in certain societies. Indeed, some people justify capital punishment on the grounds that someone who has taken another human being's life deserves to have this life taken (i.e., an eye for an eye). See e.g. Nussbaum (1999, p. 157-158) for a discussion.

Revenge is often seen as a major cause of continuing conflict over and beyond the original cause of the conflict (see, for example, Chagnon, 1988; Kim and Smith, 1993; Juah, 2002). Even more, it is sometimes argued that the desire for revenge may completely destabilize a conflict since an action by one faction is countered by an action of the other faction which is again countered by the first faction and so on. Each faction in the conflict may want to "throw the last punch". Hence, so the argument goes, revenge may lead to escalation of the conflict with dramatic or even devastating consequences for all factions. For example, commenting on the notoriously famous and bloody $19^{\text {th }}$ century feud along the Kentucky-West Virginia backcountry involving the families of the 
Hatfields and McCoys, ${ }^{1}$ Frank (1988, p. 1) observed that "[T]o this day, no one is sure how it actually started. But once underway, its pattern was one of alternating attacks, each a retaliation for the preceding, and thus also the provocation for the one to follow."

The interesting point of this paper is that, in contrast to the above arguments, the desire for seeking revenge need not lead to escalation of the conflict. Paradoxically, revenge itself even may be a reason why the conflict is stabilized. We consider a differential game of an infinitely-repeated conflict between two factions competing over a given resource. In each period, the factions exert effort in order to control the resource. Each faction has a desire to exact revenge for past destruction suffered. The destruction suffered by a player is a stock that grows according to his opponent's destructive efforts and that depreciates at the rate at which past destruction is forgotten. If in a given period a faction wins the conflict, it not only gets utility from the resource itself but also a value from exacting revenge. Hence, in our model the desire for revenge is understood as a 'prize-enhancing' phenomenon.

Within this model, we characterize open-loop and closed-loop equilibria and show that, despite the desire for revenge, the conflict may attain a steady state with stationary effort levels of the factions. In the open-loop case, it turns out that a stable steady state is reached if the decay rate of the stock of destruction is sufficiently high, the factions are relatively homogenous and/or the value from seeking revenge is comparably low. The results in the closed-loop case are even stronger. Here we identify a selfdeterrence effect. Each faction knows that its opponent will increase future effort if the faction increases effort today. Anticipating the retaliation of the opponent, the faction has an incentive to exert lower effort today. As consequence of the self-deterrence effect, the

\footnotetext{
${ }^{1}$ See Rice (1982) for an account of the Hatfield-McCoy's almost forty-year feud.
} 
closed-loop equilibrium may attain a stable steady state even if the open-loop equilibrium does not. More importantly, the self-deterrence effect may be so strong that the effort levels of the factions in the steady state are lower than the effort levels when the factions do not have a desire for revenge. This is what we call the paradox of revenge as the desire for retaliation has a deescalating impact on the conflict.

These insights are important. Revenge is often seen a major destabilizing element in conflicts. The consequences are expected to be dramatic for the factions with a total loss of human life and property. Our results show that this may not be true, but that revenge itself may be a reason why conflicts are stabilized. Such a result may help to explain why devastating conflicts eventually become stabilized even though it is known that the factions have a desire for retaliation. A good example may be the conflict between Protestants and the Catholics in Ireland. After a long time of action and counteraction, today the effort levels of the two factions is rather low and the conflict seems to be almost resolved. Of course, there may be other reasons for the resolution of the conflict (e.g. third party intervention), but the self-deterrence effect identified in our analysis may also contribute to the explanation of this observation. A similar line of reasoning may be applied to the end of the Cold War between the NATO countries and the members of the Warsaw Pact during the nineties.

The preceding point implies that revenge plays a role analogous to tit-for-tat strategies in repeated prisoner-dilemma type games insofar the desire to exact revenge (i.e., punishment) may lead to socially desirable or co-operative outcomes. However, a key difference between tit-for-tat strategy and exacting revenge (as modeled in this paper) is that in tit-for-tat, the player who retaliates does not derive utility from the 
revenge per se. He only derives a positive utility if his retaliatory action causes his opponent to co-operate in the future. Hence tit-for-tat - as modeled in repeated games - is forward-looking ${ }^{2}$ while exacting revenge - as modeled in this paper and in reality - is backward-looking. ${ }^{3}$ This distinction is akin to the legal and philosophical discussions of punishment for the purpose of deterrence and reform vis-à-vis punishment for the purpose of atonement (justice). It is the basis of the legal debate on the merits of retributive justice vis-à-vis restorative justice. This difference in perspectives explains why some South Africans were not satisfied with the mandate and job of the Truth and Reconciliation Commission ${ }^{4}$ in post-apartheid South Africa.

In a recent paper, Jaeger and Paserman (2007) found that in the Israeli-Palestinian conflict, violence by the Palestinians is a good predictor of Israeli counter attacks (violence). However, the same is not true of the Palestinians. That is, Israeli attacks do not predict Palestinian counter attacks. Using our model, we offer an alternative explanation of this puzzling result which complements Jaeger and Paserman's (2007) explanation.

To be sure, there is a wide literature on contests and conflicts. However, our work

\footnotetext{
${ }^{2}$ Commenting on the attractiveness of tit-for-tat, Axelrod (1984, p. 54) observed that "[W]hat accounts for tit-for-tat's robust success is its combination of being nice, retaliatory, forgiving and clear. Its niceness prevents it from getting into unnecessary trouble. Its retaliation discourages the other side from persisting whenever defection is tried. Its forgiveness helps restore mutual co-operation. And its clarity makes it intelligible to the other player, thereby eliciting long-term co-operation." For a critique of this far-reaching claim, see Martinez-Coll and Hirshleifer (1991) and Binmore (1998).

${ }^{3}$ As we argue in our concluding remarks, our revenge equilibria are renegotiation-proof.

${ }^{4}$ The official government webpage of South Africa's Truth and Reconciliation Commission is http://www. doj.gov.za/trc/. The report of the commission is available at http://www.info.gov.za/otherdocs/2003/trc/
} 
will be the first in the economics literature to examine revenge in conflicts. ${ }^{5}$ There is, of course, a literature which studies the conditions under which conflicts escalate or end. Examples are Nalebuff (1986), Fearon (1994), Carlson (1995), Bester and Konrad (2005), Konrad and Kovenock (2005), and Hausken (2008). Carment and Rowlands (1998), Siqueira (2003), Chang et al. (2007) and Amegashie and Kutsoati (2007) examine third-party intervention in conflicts. Garfinkel and Skarpedas (2000) studied how conflict can arise in a world of complete information, and Skaperdas (1992) investigated the conditions for peace and conflict in world with no property rights. But none of these studies has focused on the role of a desire for revenge. ${ }^{6}$

The paper is organized as follows. The next section presents a differential game model of a conflict between two factions that have a desire for revenge. As a benchmark, section 3 derives the equilibrium in the case where the factions do not obtain a benefit from retaliation. In Section 4 and 5 we characterize the open-loop and closed-loop equilibria, respectively. Section 6 discusses our results and section 7 concludes the paper.

\footnotetext{
${ }^{5}$ An exception is Jaeger and Paserman (2007) who undertake an empirical analysis of violence in the Israeli-Palestinian conflict. Unlike economists, the role of revenge in wars, conflicts, and social relationships has been studied by philosophers, legal scholars, political scientists, and psychologists. Examples are the works of Chagnon (1988), Elster (1990), Stuckless and Goranson (1992), Kim and Smith (1993), Suny (1993), Bloom (2001), Juah (2002), Knutson (2004) and Orth (2004).

${ }^{6}$ Our model is also related to that of Wirl (1994) who considers an infinitely-repeated rent-seeking contest modeled as a differential game. Similar to our model, a player's valuation in Wirl's model depends on a state variable which is influenced by his opponent's efforts and his own effort increases his opponent's valuation. However, there are important differences to our approach. First, Wirl's model only contains one state variable as opposed to two state variables in our model. Second and more importantly, Wirl does not take into account the players' desire to seek revenge. Indeed, even though Wirl also identifies a kind of deterrence effect, the missing revenge component in his model implies that he cannot derive the paradoxical results that revenge itself leads to stabilization of conflicts and that the effort of the factions with the desire for seeking revenge may be lower than without this desire. Finally, his model cannot explain the finding in Jaeger and Paserman (2007).
} 


\section{A model of revenge in conflicts}

Consider two factions, 1 and 2, in an infinitely-repeated conflict (war). The beginning of time is period 0 . The original cause of the conflict is a given resource. For example, in the Israeli-Palestinian conflict the resource may be land which is used for settlements. The factions compete for this resource in every period t. Denote the effort that faction $\mathrm{i}=1,2$ expends in order to win the conflict in period $t$ by $x_{i}(t)$. Effort of faction $i$ causes a cost denoted by the function $C^{i}\left[x_{i}(t)\right]$ which is increasing and convex, i.e. $C_{x_{i}}^{i}\left[x_{i}(t)\right]>0$ and $C_{\mathrm{x}_{\mathrm{i}} \mathrm{X}_{\mathrm{i}}}^{\mathrm{i}}\left[\mathrm{x}_{\mathrm{i}}(\mathrm{t})\right]>0$ where subscripts denote derivatives. We allow the cost function to be different for the two factions so that the conflict may be among heterogeneous players. The faction with the higher military capability has the lower cost of effort. Note that we do not make a distinction between offensive effort and defensive effort. This would complicate the model without affecting our main results. Indeed, the distinction is not necessary insofar as offensive effort could also be a form of defense.

The probability that faction $\mathrm{i}$ wins the conflict in period $\mathrm{t}$ is given by the contest success function $P^{i}\left[x_{i}(t), x_{j}(t)\right]$, where $i=1,2, j \neq i$. The contest success function satisfies

$$
\begin{aligned}
& P_{x_{i}}^{i}\left[x_{i}(t), x_{j}(t)\right]>0, \\
& P_{x_{j}}^{i}\left[x_{i}(t), x_{j}(t)\right]<0, \\
& P^{i}[x, x]=\frac{1}{2} .
\end{aligned}
$$

According to (1) and (2), a faction's winning probability is increasing in the faction's own effort and decreasing in the effort of the faction's opponent. Equation (3) states that equal efforts levels imply an equal winning probability of one half for both factions. 
These properties define a modest set of conditions imposed on the contest success function. They are satisfied by, for example, Tullock's ratio-form function $P^{i}\left[x_{i}(t), x_{j}(t)\right]=x_{i}(t)^{\eta} /\left[x_{i}(t)^{\eta}+x_{j}(t)^{\eta}\right]$ and Hirshleifer's difference-form function $\mathrm{P}^{\mathrm{i}}\left[\mathrm{x}_{\mathrm{i}}(\mathrm{t}), \mathrm{x}_{\mathrm{j}}(\mathrm{t})\right]=\exp \left\{\eta \mathrm{x}_{\mathrm{i}}(\mathrm{t})\right\} /\left[\exp \left\{\eta \mathrm{x}_{\mathrm{i}}(\mathrm{t})\right\}+\exp \left\{\eta \mathrm{x}_{\mathrm{j}}(\mathrm{t})\right\}\right]$ with $\eta>0$.

If a faction is successful in the period t conflict, it controls the resource. The direct benefit of using and possessing the resource in a given period is denoted by $\mathrm{v}>0$. For simplicity, we assume that this benefit is time independent and the same for both factions. Moreover, there is a second benefit from being successful in the conflict, namely a value of revenge. Effort by the factions results in the destruction of human life and property. This destruction fuels the conflict and creates the desire for revenge. Note that in each period, the resource (e.g., land) is up for grabs. This assumption allows us to compare our results to the benchmark case where there is no revenge but there is a contest over the resource in every period. It is also consistent with real-world conflicts like the Israeli-Palestinian conflict where exacting revenge and fighting over land occur simultaneously or appear to be inextricably linked.

In period $t$, the value of revenge to faction $i$ is given by

$$
R_{i}(t)=R\left[s_{j}(t)\right]
$$

where $s_{j}(t)$ denotes the accumulated stock of destruction inflicted by faction $j$ on faction $i$. The revenge function $\mathrm{R}$ is supposed to satisfy

$$
\begin{aligned}
& \mathrm{R}\left[\mathrm{s}_{\mathrm{j}}(\mathrm{t})\right]>0, \quad \text { if } \mathrm{s}_{\mathrm{j}}(\mathrm{t})>0, \\
& \mathrm{R}\left[\mathrm{s}_{\mathrm{j}}(\mathrm{t})\right]=0, \quad \text { if } \mathrm{s}_{\mathrm{j}}(\mathrm{t})=0, \\
& \mathrm{R}_{\mathrm{s}_{\mathrm{j}}}\left[\mathrm{s}_{\mathrm{j}}(\mathrm{t})\right]>0, \quad \text { for all } \mathrm{s}_{\mathrm{j}}(\mathrm{t}) \geq 0 .
\end{aligned}
$$


Equation (5) means that a faction has a positive valuation for revenge, if the cumulative destruction of its property and human life caused by the other faction is positive.

According to (6), the valuation is zero, if there has not been any loss of human lives or property. Equation (7) states that the higher is the cumulative destruction suffered the higher is the value of revenge. ${ }^{7}$

The accumulated stock of destruction inflicted by faction $\mathrm{i}$ on faction $\mathrm{j}$ evolves through time according to the law of motion

$$
\dot{\mathrm{s}}_{\mathrm{i}}(\mathrm{t})=\mathrm{x}_{\mathrm{i}}(\mathrm{t})-\delta \mathrm{s}_{\mathrm{i}}(\mathrm{t})
$$

with $0 \leq \delta \leq 1$ and the initial condition $\mathrm{s}_{\mathrm{i}}(0)=\mathrm{s}_{\mathrm{i} 0}$. Equation (8) shows that in period $\mathrm{t}$ the accumulated stock of destruction increases with faction i's effort in period t and may decay at rate $\delta$. Decay is due to the fact that, for example, destroyed buildings are rebuilt resulting in people forgetting some (if $0<\delta<1$ ) or all (if $\delta=1$ ) of the past destruction of buildings and so may no longer receive a value of revenge from it. People may also forget past destruction or their desire for revenge may wane even if there is no such reconstruction of buildings.

The instantaneous net benefit of faction $\mathrm{i}$ in period t equals the expected prize of winning the conflict, $P^{i}\left[x_{i}(t), x_{j}(t)\right]\left[v+R\left[s_{j}(t)\right]\right]$, less the effort cost, $C^{i}\left[x_{i}(t)\right]$. The present value of faction i's net benefit can therefore be written as

\footnotetext{
${ }^{7}$ It is important to note that revenge is fueled by past destruction not current destruction. Hence, it may be argued that the past stock of destruction $\mathrm{s}_{\mathrm{j}}(\mathrm{t}-1)$ instead of the current stock $\mathrm{s}_{\mathrm{j}}(\mathrm{t})$ should determine the value of revenge in period t. But in a continuous-time framework like ours this distinction vanishes. Formally, suppose the length of a time period in a discrete-time framework is not unity but some $\varepsilon>0$. The past stock of destruction is then given by $\mathrm{s}_{\mathrm{j}}(\mathrm{t}-\varepsilon)$, and the continuous-time framework is attained in the limiting case of $\varepsilon \rightarrow 0$ where the length of a time period becomes zero.
} 


$$
\mathrm{W}^{\mathrm{i}}=\int_{0}^{\infty}\left\{\mathrm{P}^{\mathrm{i}}\left[\mathrm{x}_{\mathrm{i}}(\mathrm{t}), \mathrm{x}_{\mathrm{j}}(\mathrm{t})\right]\left[\mathrm{v}+\mathrm{R}\left[\mathrm{s}_{\mathrm{j}}(\mathrm{t})\right]\right]-\mathrm{C}^{\mathrm{i}}\left[\mathrm{x}_{\mathrm{i}}(\mathrm{t})\right]\right\} \mathrm{e}^{-\mathrm{rt}} \mathrm{dt}
$$

where $r>0$ is the common discount rate. Faction i maximizes (9) subject to the law of motion in equation (8). This formulation makes visible that our modeling emphasizes the 'prize-enhancing' property of revenge: Revenge acts as if it increases the prize a faction obtains when it wins the conflict, and this effect is more pronounced the higher the stock of destruction inflicted by the other faction in the past. ${ }^{8}$

Our model may omit several of aspects revenge in real world conflicts. For example, our framework implicitly assumes that a faction obtains a benefit from revenge only if it is successful in the conflict. In real world conflicts, a benefit from revenge may also accrue to the loser of the conflict. But this effect can easily be integrated in our model without changing the main insights. To see this, assume that faction i's benefit from revenge is $Z\left[\mathrm{~s}_{j}(t)\right]$ if it wins the conflict in period $t$ and $\gamma Z\left[\mathrm{~s}_{\mathrm{j}}(\mathrm{t})\right]$ with $\gamma<1$ if it loses the conflict in period $t$. The latter event takes place with probability $1-\mathrm{P}^{\mathrm{i}}\left[\mathrm{x}_{\mathrm{i}}(\mathrm{t}), \mathrm{x}_{\mathrm{j}}(\mathrm{t})\right]$. The condition $\gamma<1$ means that the value of revenge is lower if the faction loses the conflict than if it wins the conflicts, which seems to be a plausible assumption. Defining $\mathrm{R}\left[\mathrm{s}_{\mathrm{j}}(\mathrm{t})\right]:=(1-\gamma) \mathrm{Z}\left[\mathrm{s}_{\mathrm{j}}(\mathrm{t})\right]$, the instantaneous net benefit of faction $\mathrm{i}$ in period $\mathrm{t}$ reads $\mathrm{P}^{\mathrm{i}}\left[\mathrm{x}_{\mathrm{i}}(\mathrm{t}), \mathrm{x}_{\mathrm{j}}(\mathrm{t})\right]\left[\mathrm{v}+\mathrm{R}\left[\mathrm{s}_{\mathrm{j}}(\mathrm{t})\right]\right]+\gamma \mathrm{Z}\left[\mathrm{s}_{\mathrm{j}}(\mathrm{t})\right]-\mathrm{C}^{\mathrm{i}}\left[\mathrm{x}_{\mathrm{i}}(\mathrm{t})\right]$. Hence, the only difference to the

\footnotetext{
${ }^{8}$ It is important to note that the positive value of revenge does not reflect masochistic preferences. A faction does not derive satisfaction from suffering destruction. Destruction is costly to the victim. However, given that destruction has been suffered in the past, the victim derives satisfaction from exacting revenge.
} 
instantaneous net benefit in equation (9) is the term $\gamma \mathrm{Z}\left[\mathrm{s}_{\mathrm{j}}(\mathrm{t})\right]$. It is straightforward to show that this term leaves our results qualitatively unchanged. ${ }^{9}$

Moreover, one may argue that our modeling of revenge ignores the possibility that past destruction is forgotten or taken out of future revenge-seeking calculus after it has been successfully avenged. We do not make this assumption for several reasons: First, the destruction suffered by a faction is narrated by older generations to younger generations, regardless of whether they were successfully avenged. Long-standing foes continually remind themselves of the destruction suffered from the other group. Such constant reminders could bring back memories of past destruction that was successfully avenged. ${ }^{10}$ Second, the avenger will invariably suffer some losses in the current period even if the revenge was successful. Hence, current destruction suffered in the process of exacting revenge or an enemy's destructive response to one's previous revenge could bring back memories of past destruction that was successfully avenged. Revenge may create a cycle of animosity which may draw its momentum from past destruction suffered several periods ago. Third, in a study of crime victims, Orth (2004) found that perpetrator punishment only transitorily satisfied victims' feelings of revenge. Hence, the feeling of revenge may survive for several periods even if the perpetrator has already been punished. Fourth, one of the key results of this paper is that a conflict need not escalate even if there is the desire for revenge. If we were to assume that past destruction is completely forgotten after it has been successfully avenged we would be making an

\footnotetext{
${ }^{9}$ In the open-loop case this term only affects the dynamics of the co-state variables, but leaves unaltered the choice of effort levels and the dynamics of the state variables. Under the closed-loop assumption, we can find examples similar to those derived in the subsequent analysis even if the term $\gamma Z\left[\mathrm{sj}_{j}(\mathrm{t})\right]$ is present. ${ }^{10}$ Indeed, the revenge function (i.e., satisfaction from revenge) could change over time depending how radical the current generation is relative to previous generations. For simplicity, we keep the revenge function constant and only allow the state variables to change over time.
} 
assumption that necessarily biases our results towards this non-escalation outcome.

Instead, we show that a conflict need not escalate even if successfully-avenged destruction is not forgotten.

Furthermore, since in our model the desire for seeking revenge is motivated by the past, it goes against economists' intuition of letting bygones be bygones. In standard economics, it is usually argued that sunk costs should not matter. However, in reality, sunk costs matter. ${ }^{11}$ And one such example is the desire to exact revenge. This desire may stem from preferences that reflect loss aversion (Kahneman and Tversky, 1979). For example, in a war, one may want to exact revenge because not doing so is tantamount to losing the war (McAfee et al, 2007).

Finally, it may be argued that our model ignores the fact that destruction by one faction imposes a direct cost on the other faction. Such a direct cost may be incorporated in our analysis by subtracting from the instantaneous net benefit of faction $i$ the term $\beta x_{j}(t)$ with $\beta>0$. However, this would leave our results qualitatively unchanged: In the open-loop case, faction $\mathrm{i}$ takes as given the effort of faction $\mathrm{j}$ so that the additive term $\beta \mathrm{x}_{\mathrm{j}}(\mathrm{t})$ does not change the choice of faction $\mathrm{i}$. The term will enter the optimality conditions under the closed loop assumption, but it can be shown that the conclusions derived form our analysis of this case are not changed. Indeed, we can show that the main conclusion of our closed-loop analysis is strengthened (see footnote 17$).^{12}$

\footnotetext{
${ }^{11}$ See the examples in McAfee et al., (2007) and the references therein.

${ }^{12}$ A further point is that a faction's value of revenge may depend not only positively on the stock of destruction of the other faction, but also negatively on its own stock of destruction, i.e. $R_{i}(t)=R\left[s_{i}(t), s_{j}(t)\right]$ with $\mathrm{R}_{\mathrm{Si}}[]<$.0 . Our analysis ignores this kind of 'relative' revenge. A possible argument is the psychological phenomenon, formalized by Kahneman and Tversky (1979), where gains (in this case, destruction inflicted on others) are weighted less than losses (i.e., destruction suffered). Here we assume that past destruction inflicted on others is completely disregarded in a faction's revenge-seeking calculus.
} 


\section{Equilibrium without revenge}

As a benchmark we consider the case without revenge. This is obtained as a special case of the model presented in the previous section when we set $\mathrm{R}\left[\mathrm{s}_{\mathrm{j}}(\mathrm{t})\right] \equiv 0$ so that there is no prize-enhancing effect of revenge. Faction i's dynamic optimization problem in (8) and (9) then boils down to a continuum of static maximization problems, i.e. in every period t faction i maximizes the instantaneous net benefit $P^{\mathrm{i}}\left[\mathrm{x}_{\mathrm{i}}(\mathrm{t}), \mathrm{x}_{\mathrm{j}}(\mathrm{t})\right] \mathrm{v}-\mathrm{C}^{\mathrm{i}}\left[\mathrm{x}_{\mathrm{i}}(\mathrm{t})\right]$. The first order condition of this maximization problem is

$$
P_{x_{i}}^{i}\left[x_{i}(t), x_{j}(t)\right] v=C_{x_{i}}^{i}\left[x_{i}(t)\right]
$$

This first order condition is the same as in the standard conflict model without revenge. It equates the expected marginal prize and the marginal cost of effort. Equation (10) for $i=1,2$ determines the equilibrium effort levels of both factions. These equilibrium effort levels imply a time path for the factions' stock of destruction according to the law of motion (8). However, in the absence of a desire to exact revenge, there is no feedback of the stock of destruction on the equilibrium effort levels. Hence, the effort levels are stationary in the sense that they are the same in every period.

To illustrate and for later purpose we introduce specific functional forms of the cost functions and the contest success function. The cost functions are assumed to be quadratic, i.e. $C\left[x_{i}(t)\right]=c_{i} x_{i}(t)^{2} / 2$ with $c_{1}, c_{2}>0$. In case of heterogeneous factions we assume, without loss of generality, that $\mathrm{c}_{1}<\mathrm{c}_{2}$ so that, following a standard interpretation in the literature on contests, faction 1 is the stronger faction. The contest success function is supposed to be linear 


$$
\mathrm{P}^{\mathrm{i}}\left[\mathrm{x}_{\mathrm{i}}(\mathrm{t}), \mathrm{x}_{j}(\mathrm{t})\right]=\frac{1}{2}+\eta\left[\mathrm{x}_{\mathrm{i}}(\mathrm{t})-\mathrm{x}_{j}(\mathrm{t})\right]
$$

with $\eta>0$. Such a linear difference-form function is used, for example, by Che and Gale (2000). For our purpose, the functional form in equation (11) is easier to work with than the Tullock ratio-form or the Hirshleifer difference-form contest success function. At the same time, (11) satisfies the basic properties defined by (1) - (3). Note also that the parameter $\eta$ can be interpreted in the same way as in the Tullock and Hirshleifer functions. It reflects the sensitivity of the winning probability with respect to the effort levels. $^{13}$

Using this specification of our model in (10) and (8) and indicating the equilibrium values in the case without revenge by a tilde yields

$$
\begin{aligned}
& \widetilde{\mathrm{x}}_{\mathrm{i}}(\mathrm{t})=\frac{\eta \mathrm{v}}{\mathrm{c}_{\mathrm{i}}}, \\
& \widetilde{\mathrm{s}}_{\mathrm{i}}(\mathrm{t})=\widetilde{\mathrm{s}}_{\mathrm{i}}^{\infty}+\left(\mathrm{s}_{\mathrm{i} 0}-\widetilde{\mathrm{s}}_{\mathrm{i}}^{\infty}\right) \mathrm{e}^{-\delta \mathrm{t}},
\end{aligned}
$$

with

$$
\widetilde{\mathrm{s}}_{\mathrm{i}}^{\infty}=\frac{\eta \mathrm{v}}{\delta \mathrm{c}_{\mathrm{i}}}
$$

For later reference two observations are important. First, the equilibrium effort level of faction $i$ in (12) is decreasing in its cost parameter $c_{i}$, but independent of faction $j$ 's cost parameter $c_{j}$. The latter result is due to the linear contest success function, ${ }^{14}$ but we will see that this result is not true when the factions have a desire to exact revenge. Second,

\footnotetext{
${ }^{13}$ In contrast to the Tullock and Hirshleifer functions, we have to assume that the term $\eta\left[x_{i}(t)-x_{j}(t)\right]$ is smaller than one half in absolute terms since otherwise the winning probabilities of the factions may become negative and/or larger than one.

${ }^{14}$ In game-theoretic terms, each player has a strictly dominant strategy since player i’s best-response function is independent of player j's effort level. This also means that the equilibrium is unique.
} 
according to (13) and (14), faction i's stock of destructions will always attain a stable stationary state $\widetilde{\mathrm{s}}_{\mathrm{i}}^{\infty}$ as long as the decay rate $\delta$ is positive. In the next section, we will show that revenge may change the stability properties of the conflict.

\section{Open-loop equilibrium}

Let us now turn to the case with revenge. The maximization problem defined by (8) and (9) then becomes a dynamic problem since faction i's net benefit is affected by faction j's stock of destruction. This strategic interdependence is the reason why we obtain a noncooperative differential game between the two factions. We first look for an open-loop equilibrium and later find a closed-loop (Markovian) equilibrium of this game.

In the context of exacting revenge, an open-loop equilibrium may be appropriate for several reasons. First, under open-loop strategies the factions condition their effort levels on calendar time only. As noted by Hume (1898), revenge is an emotionally charged reaction leading people who seek revenge to knowingly ignore certain consequences of their actions. ${ }^{15}$ When people decide to take revenge, they may not take into account the possibility that their actions could lead to retaliation by their opponent. They just do it (i.e., seek revenge). This is consistent with the rationale behind the openloop strategy where the feedback through the state variable (i.e., the level of accumulated destruction) is ignored by a faction. Second, an open-loop equilibrium is based on the

\footnotetext{
${ }^{15}$ Hume (1898, appendix II) notes that "[W]ho see not that vengeance, from the force alone of passion, may be so eagerly pursued as to make us knowingly neglect every consideration of ease, interest, and safety and, like some vindictive animals, infuse our very souls into the wounds we give an enemy." This, however, does not mean that the desire for revenge is not driven by some modicum of rational decision making. It is only less so. Romer (2000) presents a model and examples of how our feelings (emotions) and thoughts affect our decision-making. The fact remains though, as echoed by Hume, that people could go to great lengths to exact revenge.
} 
assumption that each player can pre-commit to a time-path of actions. Since the desire for revenge is an emotion, this ability to commit is supported by Frank's (1988) argument that emotions are the production functions for pre-commitment. Furthermore, to the extent that revenge is a form of punishment, our open-loop analysis is supported by recent experimental work by Casari and Luini (2006) which showed that experimental subjects did not value punishment for its deterrence but instead for the satisfaction of retaliating and these punishment choices were made with little strategic reasoning. In sum, even though the nature of strategies is an empirical question, the arguments above suggest that it is worthwhile to investigate the open loop case. Indeed, as we later show, our open-loop equilibrium sheds some light on a finding in Jaager and Paserman (2007).

Under the open-loop assumption faction i maximizes the present value of its net benefit in (9) subject to the law of motion (8). In doing so, it takes as given the time path of faction $\mathrm{j}$ 's effort level $\mathrm{x}_{\mathrm{j}}(\mathrm{t})$. The current-value Hamiltonian for faction $\mathrm{i}$ is

$$
H^{i}=P^{i}\left[x_{i}, x_{j}(t)\right]\left[v+R\left(s_{j}\right)\right]-C^{i}\left(x_{i}\right)+\lambda_{i}\left[x_{i}-\delta s_{i}\right]+\mu_{i}\left[x_{j}(t)-\delta s_{j}\right]
$$

where $\lambda_{\mathrm{i}}$ and $\mu_{\mathrm{i}}$ represent the co-state variables associated with the stock of destruction of faction $\mathrm{i}$ and the stock of destruction of faction $\mathrm{j}$, respectively. Applying the maximum principle yields the following optimality conditions

$$
\begin{aligned}
& \mathrm{P}_{\mathrm{x}_{\mathrm{i}}}^{\mathrm{i}}\left[\mathrm{x}_{\mathrm{i}}, \mathrm{x}_{\mathrm{j}}(\mathrm{t})\right]\left[\mathrm{v}+\mathrm{R}\left(\mathrm{s}_{\mathrm{j}}\right)\right]-\mathrm{C}_{\mathrm{x}_{\mathrm{i}}}^{\mathrm{i}}\left(\mathrm{x}_{\mathrm{i}}\right)+\lambda_{\mathrm{i}}=0, \\
& \dot{\lambda}_{\mathrm{i}}=\mathrm{r} \lambda_{\mathrm{i}}-\mathrm{H}_{\mathrm{s}_{\mathrm{i}}}^{\mathrm{i}}=(\mathrm{r}+\delta) \lambda_{\mathrm{i}}, \\
& \dot{\mu}_{\mathrm{i}}=r \mu_{\mathrm{i}}-\mathrm{H}_{\mathrm{s}_{\mathrm{j}}}^{\mathrm{i}}=(\mathrm{r}+\delta) \mu_{\mathrm{i}}-\mathrm{P}^{\mathrm{i}}\left[\mathrm{x}_{\mathrm{i}}, \mathrm{x}_{\mathrm{j}}(\mathrm{t})\right] \mathrm{R}_{\mathrm{s}_{\mathrm{j}}}\left(\mathrm{s}_{\mathrm{j}}\right) .
\end{aligned}
$$


The co-state variable $\lambda_{\mathrm{i}}$ measures the shadow prize of the state variable $\mathrm{s}_{\mathrm{i}}$. Under the open-loop assumption, the state variable $s_{i}$ does not affect faction i's instantaneous net benefit and, thus, has no value for faction $i$. It follows $\lambda_{\mathrm{i}}=0 .{ }^{16}$ Inserting this finding into equation (15) gives

$$
\mathrm{P}_{\mathrm{x}_{\mathrm{i}}}^{\mathrm{i}}\left[\mathrm{x}_{\mathrm{i}}, \mathrm{x}_{\mathrm{j}}(\mathrm{t})\right]\left[\mathrm{v}+\mathrm{R}\left(\mathrm{s}_{\mathrm{j}}\right)\right]-\mathrm{C}_{\mathrm{x}_{\mathrm{i}}}^{\mathrm{i}}\left(\mathrm{x}_{\mathrm{i}}\right)=0
$$

This equation looks very similar to the corresponding equation (10) in the case without revenge. It equates the expected marginal prize and the marginal effort cost of faction i. However, there is an important difference. The expected marginal prize now depends not only on v, but also on the value of revenge R. As the latter depends on the stock of destruction of faction $\mathrm{j}$, it follows that the equilibrium effort level of faction i need not be stationary except in a steady state: Faction i's choice of effort in a given period affects the stock of destruction inflicted by faction i on faction $\mathrm{j}$ and, thus, faction $\mathrm{j}$ 's choice of effort in the next period via the value of revenge. This in turn influences the stock of destruction inflicted by faction $\mathrm{j}$ on faction $\mathrm{i}$ and faction i's choice of effort in the period thereafter. In sum, the effort levels of the factions may change over time.

In order to illustrate the consequences of this insight, we again refer to the quadratic cost functions and the linear contest success function in (11). In addition, assume that the value of revenge is linear in the stock of destruction, i.e., $R\left(s_{j}\right)=\alpha s_{j}$ with

\footnotetext{
${ }^{16}$ Formally, $\lambda_{i}(t)=0$ follows from (17) and the transversality condition $\lim _{t \rightarrow \infty} \mathrm{e}^{-\mathrm{rt}} \lambda_{\mathrm{i}}(\mathrm{t}) \mathrm{s}_{\mathrm{i}}(\mathrm{t})=0$ which has to be satisfied for all feasible time paths of the state variable $\mathrm{s}_{\mathrm{i}}(\mathrm{t})$. To see this, note that the solution to the differential equation (17) reads $\lambda_{\mathrm{i}}(\mathrm{t})=\mathrm{Ke}^{(\mathrm{r}+\delta) \mathrm{t}}$ where $\mathrm{K}$ is a given constant. Inserting into the transversality conditions gives $\lim _{\mathrm{t} \rightarrow \infty} \mathrm{Ke}^{\delta \mathrm{t}} \mathrm{s}_{\mathrm{i}}(\mathrm{t})=0$. As this condition has to be satisfied for all $\mathrm{s}_{\mathrm{i}}(\mathrm{t})$, it follows $\mathrm{K}=0$ and, thus, $\lambda_{\mathrm{i}}(\mathrm{t})=0$ as stated.
} 
$\alpha>0$. Using these specifications in (19) and solving with respect to faction i's effort yields

$$
x_{i}^{*}=\frac{\eta v}{c_{i}}+\frac{\eta \alpha}{c_{i}} s_{j}^{*},
$$

where the star indicates optimal values under the open loop assumption. For interpretative purposes note that we can write $(20)$ as $\mathrm{x}_{\mathrm{i}}{ }^{*}=\left(\eta / \mathrm{c}_{\mathrm{i}}\right)\left[\mathrm{v}+\mathrm{R}\left(\mathrm{s}_{\mathrm{j}}{ }^{*}\right)\right]$. In the openloop equilibrium, player $\mathrm{i}$ treats the time path of $\mathrm{x}_{\mathrm{j}}$ and, for that matter $\mathrm{s}_{\mathrm{j}}$, as fixed. It follows that player $\mathrm{i}$ in each period sees himself as being in a stationary (static) contest with prize $\mathrm{v}+\mathrm{R}\left(\mathrm{s}_{\mathrm{j}}\right)$. This is analogous to the case without revenge where in each period a contest with prize $\mathrm{v}$ takes place. But with revenge the conflict shifts over time because each faction's value of revenge, $\mathrm{R}(\cdot)$, changes with time. In this sense the open-loop equilibrium with revenge is stationary but with a different prize in each period.

Inserting (20) into the state equation (8) yields

$$
\dot{\mathrm{s}}_{\mathrm{i}}^{*}=\frac{\eta \mathrm{v}}{\mathrm{c}_{\mathrm{i}}}-\delta \mathrm{s}_{\mathrm{i}}^{*}+\frac{\eta \alpha}{\mathrm{c}_{\mathrm{i}}} \mathrm{s}_{\mathrm{j}}^{*} \text {. }
$$

With $\mathrm{i}=1,2, \mathrm{j} \neq \mathrm{i}$, equation (21) represents a two-dimensional system of linear differential equations in $s_{1}$ and $s_{2}$. Determining the eigenvalues and the eigenvectors of this system yields the solution

$$
s_{i}^{*}(t)=s_{i}^{\infty *}+\frac{k_{i} \sqrt{c_{i}}-k_{j} \sqrt{c_{j}}}{2 \sqrt{c_{i}}} e^{\theta_{1} t}+\frac{k_{i} \sqrt{c_{i}}+k_{j} \sqrt{c_{j}}}{2 \sqrt{c_{i}}} e^{\theta_{2} t}
$$

where

$$
\theta_{1}=-\delta-\frac{\alpha \eta}{\sqrt{\mathrm{c}_{1} \mathrm{c}_{2}}}, \quad \theta_{2}=-\delta+\frac{\alpha \eta}{\sqrt{\mathrm{c}_{1} \mathrm{c}_{2}}}
$$

represent the eigenvalues of (21) and where 


$$
\mathrm{s}_{\mathrm{i}}^{\infty *}=\frac{\eta \mathrm{v}\left(\delta \mathrm{c}_{\mathrm{j}}+\eta \alpha\right)}{\delta^{2} \mathrm{c}_{\mathrm{i}} \mathrm{c}_{\mathrm{j}}-\eta^{2} \alpha^{2}}
$$

is the steady state value of accumulated destruction inflicted by faction $\mathrm{i}$ on faction $\mathrm{j}$. Moreover, $\mathrm{k}_{\mathrm{i}}=\mathrm{s}_{\mathrm{i} 0}-\mathrm{s}_{\mathrm{i}}^{\infty *}$ is a given constant measuring the difference between the initial value and the steady state value of accumulated destruction.

In the case without revenge, we found that the conflict is stationary and leads to a stable steady state. The stability of the open-loop equilibrium with revenge is determined by the eigenvalues given by (23). The dynamics of the stock of destruction yields a stable steady state if and only if both eigenvalues are negative. While $\theta_{1}$ is always negative, $\theta_{2}$ may be non-negative. However, $\theta_{2}<0$ if $\delta \sqrt{c_{1} c_{2}}>\eta \alpha$. This condition also ensures that $\mathrm{s}_{\mathrm{i}}^{\infty^{*}}>0$ for $\mathrm{i}=1,2$. This immediately proves

Proposition 1: If factions in a conflict use open-loop strategies and have a desire to exact revenge, then the conflict reaches a steady state if and only if $\delta \sqrt{\mathrm{c}_{1} \mathrm{c}_{2}}>\eta \alpha$. This is an important result. At first glance, one might think that revenge necessarily destabilizes the conflict. An increase in effort of faction i raises the value of revenge and effort of faction $\mathrm{j}$. This in turn raises the value of revenge and effort of faction $\mathrm{i}$, and so on. Proposition 1 shows that despite such a 'spiral of violence' the conflict may not escalate but may reach a steady state with stationary effort levels of both factions.

The existence of a steady state depends on the model parameters. From the condition $\delta \sqrt{\mathrm{c}_{1} \mathrm{c}_{2}}>\eta \alpha$ we obtain 
Corollary 1: If factions in a conflict use open-loop strategies and have a desire to exact revenge, then the conflict reaches a steady state if, ceteris paribus,

(a) the decay rate $\delta$ is relatively high,

(b) the revenge parameter $\alpha$ is relatively low,

(c) the difference between the cost parameters $\mathrm{c}_{1}$ and $\mathrm{c}_{2}$ is relatively low.

Proof: The proof of (a) and (b) is straightforward from the condition $\delta \sqrt{\mathrm{c}_{1} \mathrm{c}_{2}}>\eta \alpha$. In order to prove (c) suppose $\mathrm{c}_{1}$ and $\mathrm{c}_{2}$ satisfy $\mathrm{c}_{1}+\mathrm{c}_{2}=\overline{\mathrm{c}}$. Then $\mathrm{c}_{1} \mathrm{c}_{2}$ is maximized at $\mathrm{c}_{1}=\mathrm{c}_{2}=\overline{\mathrm{c}} / 2$ and it is smaller the bigger is the difference between $\mathrm{c}_{1}$ and $\mathrm{c}_{2}$. Q.E.D. Corollary 1 identifies forces that may stabilize the conflict even in the presence of the desire for seeking revenge. According to (a) the conflict reaches a steady state if the decay rate is sufficiently large since then a relatively large part of past destruction is forgotten and the incentive for exerting revenge is weakened. The same is true if the desire for revenge per se is relatively low as shown by point (b). Point (c) states that a conflict between relatively homogenous factions is less likely to escalate than a conflict between relatively heterogeneous factions. The reason is that in a heterogeneous conflict the faction (say faction i) with a very high military capability (i.e., very low $c_{i}$ ) exerts a very high level of effort according to (20). This increases the destruction imposed on the faction (say faction $\mathrm{j}$ ) with the very low military capability (i.e., high $\mathrm{c}_{\mathrm{j}}$ ) which significantly increases his value from revenge. So while faction $\mathrm{j}$ has a high $\mathrm{c}_{\mathrm{j}}$, its high value of revenge stemming from faction i's action causes it to increase effort substantially. This, in turn, causes faction i to increase its effort resulting in an unending 
vicious cycle of revenge. In a conflict among homogenous factions this effect is less severe so that the conflict need not escalate but instead reaches a steady state.

If a steady state is attained, the corresponding effort levels are obtained by inserting (24) into (20). Straightforward calculations yield the following proposition: Proposition 2: Suppose factions in a conflict are motivated by the desire to seek revenge and use open-loop strategies. If the conflict reaches a steady state, then aggregate effort and aggregate destruction are both increasing in the difference between the military capabilities of the factions.

Proof: From (20) and (24) we obtain

$$
\mathrm{x}_{1}^{\infty^{*}}+\mathrm{x}_{2}^{\infty^{*}}=\eta \mathrm{v}\left(\frac{\mathrm{c}_{1}+\mathrm{c}_{2}}{\mathrm{c}_{1} \mathrm{c}_{2}}+\frac{2 \delta+\eta \alpha\left(\mathrm{c}_{1}+\mathrm{c}_{2}\right) / \mathrm{c}_{1} \mathrm{c}_{2}}{\delta^{2} \mathrm{c}_{1} \mathrm{c}_{2}-\eta^{2} \alpha^{2}}\right)
$$

Holding $\mathrm{c}_{1}+\mathrm{c}_{2}$ fixed, it is obvious that aggregate effort in the steady state is decreasing in $c_{1} c_{2}$. Then it follows from the first part of the proof of corollary 1 that aggregate effort in the steady state is higher, the bigger is the absolute difference between $c_{1}$ and $c_{2}$ holding $c_{1}+c_{2}$ fixed. The proof for aggregate destruction in the steady state is straightforward. QED.

The intuition for this proposition is very similar to the intuition given above for part (c) of corollary 1. Hence, we would not repeat it here. However, we will discuss this proposition in a subsequent section.

We also obtain the following proposition: 
Proposition 3: Suppose factions in a conflict are motivated by the desire to seek revenge and use open-loop strategies. If the conflict reaches a steady state, then the corresponding effort levels are decreasing in the decay rate, $\delta$, and increasing in the benefit of revenge parameter, $\alpha$. Moreover, the steady state effort level of faction $i$ is not only inversely related to $\mathrm{c}_{\mathrm{i}}$ but also to $\mathrm{c}_{\mathrm{j}}$.

Proof: From (24) and (20) we obtain

$$
\begin{aligned}
& \frac{\partial \mathrm{x}_{\mathrm{i}}^{\infty *}}{\partial \alpha}=\frac{\eta}{\mathrm{c}_{\mathrm{i}}}\left(\mathrm{s}_{\mathrm{j}}^{\infty *}+\alpha \frac{\partial \mathrm{s}_{\mathrm{j}}^{\infty *}}{\partial \alpha}\right)>0, \text { since } \mathrm{s}_{\mathrm{j}}^{\infty *} \text { and } \frac{\partial \mathrm{s}_{\mathrm{j}}^{\infty *}}{\partial \alpha} \text { are both positive, } \\
& \frac{\partial \mathrm{x}_{\mathrm{i}}^{\infty *}}{\partial \delta}=\frac{\eta \alpha}{\mathrm{c}_{\mathrm{i}}} \frac{\partial \mathrm{s}_{\mathrm{j}}^{\infty *}}{\partial \delta}=-\frac{\alpha v \eta^{2}\left(\delta^{2} \mathrm{c}_{\mathrm{i}} \mathrm{c}_{\mathrm{j}}+\eta^{2} \alpha^{2}+2 \alpha \delta \eta \mathrm{c}_{\mathrm{j}}\right)}{\left(\delta^{2} \mathrm{c}_{\mathrm{i}} \mathrm{c}_{\mathrm{j}}-\eta^{2} \alpha^{2}\right)^{2}}<0, \\
& \frac{\partial \mathrm{x}_{\mathrm{i}}^{\infty *}}{\partial \mathrm{c}_{\mathrm{i}}}=-\frac{\eta \mathrm{v}}{\mathrm{c}_{\mathrm{i}}^{2}}-\frac{\eta \alpha \mathrm{s}_{\mathrm{j}}^{*}}{\mathrm{c}_{\mathrm{i}}^{2}}+\frac{\eta \alpha}{\mathrm{c}_{\mathrm{i}}} \frac{\partial \mathrm{s}_{\mathrm{j}}^{\infty *}}{\partial \mathrm{c}_{\mathrm{i}}}=-\frac{\eta v \delta^{3} \mathrm{c}_{\mathrm{j}}\left(\delta \mathrm{c}_{\mathrm{j}}+\eta \alpha\right)}{\left(\delta^{2} \mathrm{c}_{\mathrm{i}} \mathrm{c}_{\mathrm{j}}-\eta^{2} \alpha^{2}\right)^{2}}<0, \\
& \frac{\partial \mathrm{x}_{\mathrm{i}}^{\infty *}}{\partial \mathrm{c}_{\mathrm{j}}}=\frac{\eta \alpha}{\mathrm{c}_{\mathrm{i}}} \frac{\partial \mathrm{s}_{\mathrm{j}}^{\infty *}}{\partial \mathrm{c}_{\mathrm{j}}}=-\frac{\eta^{2} \alpha v \delta^{2}\left(\delta \mathrm{c}_{\mathrm{i}}+\eta \alpha\right)}{\left(\delta^{2} \mathrm{c}_{\mathrm{i}} \mathrm{c}_{\mathrm{j}}-\eta^{2} \alpha^{2}\right)^{2}}<0 .
\end{aligned}
$$

This proves the proposition. (Q.E.D.)

If the decay rate is relatively high, the stock of destruction is relatively low.

Hence, the factions desire to seek revenge is comparably weak so that the steady state effort levels are relatively low as shown by the first part of Proposition 2 . The rationale of the second part is as follows: If faction i has high cost of effort, it exerts low effort to win the conflict. This is the same effect as in the case without revenge. However, with revenge, there is additional effect where the effort cost of faction $\mathrm{j}$ affects the effort level of faction $i$. If the effort cost of faction $\mathrm{j}$ increases, then faction $\mathrm{j}$ invests less effort in the conflict and has a lower stock of destruction in the steady state. As a consequence, 
faction i's value from exacting revenge declines with the consequence that faction i's effort falls.

Even though we have shown that the factions' desire for exacting revenge need not lead to an escalation of the conflict, it should be noted that the steady state effort levels in the open-loop case with revenge are always higher than the effort levels in the case without revenge (compare equation (20) with equation (12)). This will be an important point when we now turn to the closed-loop case.

\section{Closed-loop equilibrium}

The assumption of closed-loop (Markovian) strategies has the advantage that it does not require pre-commitment of the factions and that it yields subgame perfect solutions.

In contrast to open-loop strategies, closed-loop strategies assume that the factions do not condition their effort in period t on calendar time $t$, but on the state variables in period t, i.e. faction i's strategy can be written as $x_{i}(t)=\Phi^{i}\left[s_{i}(t), s_{j}(t)\right]$. Faction i now still takes as given the strategy of faction $\mathrm{j}$, but in choosing the effort level it takes into account that faction j's effort depends on the stock of destruction via the closed-loop assumption. The Hamiltonian of faction $\mathrm{i}$ is therefore

$$
H^{i}=P^{i}\left[x_{i}, \Phi^{j}\left(s_{j}, s_{i}\right)\right]\left[v+R\left(s_{j}\right)\right]-C^{i}\left(x_{i}\right)+\lambda_{i}\left[x_{i}-\delta s_{i}\right]+\mu_{i}\left[\Phi^{j}\left(s_{j}, s_{i}\right)-\delta s_{j}\right] .
$$

Applying the maximum principle yields

$$
\begin{aligned}
& \mathrm{P}_{\mathrm{x}_{\mathrm{i}}}^{\mathrm{i}} \cdot[\cdot]\left[\mathrm{v}+\mathrm{R}\left(\mathrm{s}_{\mathrm{j}}\right)\right]-\mathrm{C}_{\mathrm{x}_{\mathrm{i}}}^{\mathrm{i}}\left(\mathrm{x}_{\mathrm{i}}\right)+\lambda_{\mathrm{i}}=0, \\
& \dot{\lambda}_{\mathrm{i}}=\mathrm{r} \lambda_{\mathrm{i}}-\mathrm{H}_{\mathrm{s}_{\mathrm{i}}}^{\mathrm{i}}=(\mathrm{r}+\delta) \lambda_{\mathrm{i}}-\left[\mathrm{v}+\mathrm{R}\left(\mathrm{s}_{\mathrm{j}}\right)\right] \mathrm{P}_{\mathrm{x}_{\mathrm{j}}}^{\mathrm{i}}[\cdot] \Phi_{\mathrm{s}_{\mathrm{i}}}^{\mathrm{j}}(\cdot)-\mu_{\mathrm{i}} \Phi_{\mathrm{s}_{\mathrm{i}}}^{\mathrm{j}}(\cdot),
\end{aligned}
$$




$$
\dot{\mu}_{\mathrm{i}}=\mathrm{r} \mu_{\mathrm{i}}-\mathrm{H}_{\mathrm{s}_{\mathrm{j}}}^{\mathrm{i}}=(\mathrm{r}+\delta) \mu_{\mathrm{i}}-\mathrm{P}^{\mathrm{i}}[\cdot] \mathrm{R}_{\mathrm{s}_{\mathrm{j}}}\left(\mathrm{s}_{\mathrm{j}}\right)-\left[\mathrm{v}+\mathrm{R}\left(\mathrm{s}_{\mathrm{j}}\right)\right] \mathrm{P}_{\mathrm{x}_{\mathrm{j}}}^{\mathrm{i}}[\cdot] \Phi_{\mathrm{s}_{\mathrm{j}}}^{\mathrm{j}}(\cdot)-\mu_{\mathrm{i}} \Phi_{\mathrm{s}_{\mathrm{j}}}^{\mathrm{j}}(\cdot) .
$$

The key difference between these optimality conditions and the optimality conditions in (16) - (18) in the open-loop case are the last two terms on the RHS of (26) which contain the impact of faction i's stock of destruction on faction j's effort level, i.e., $\Phi_{s_{i}}^{j}($.$) . This$ impact is ignored by faction $\mathrm{i}$ under the open-loop assumption (implying $\lambda_{\mathrm{i}}(\mathrm{t})=0$ for all t) but is taken into account by faction i in the closed-loop case. Through two new channels, it influences the shadow price of faction i's stock of destruction $\left(\lambda_{\mathrm{i}}\right)$ and, via equation (25), faction i's choice of effort. First, if faction i increases its effort and stock of destruction, faction j's incentive to seek revenge becomes stronger. As a consequence, faction $\mathrm{j}$ raises its effort level and stock of destruction so that faction i's value of revenge goes up. This value effect is reflected by the last term in (26), i.e. $\mu_{\mathrm{i}} \Phi_{\mathrm{s}_{\mathrm{i}}}^{\mathrm{j}}($.$) . Compared to$ the open-loop case, it increases $\lambda_{\mathrm{i}}$ and gives faction i the incentive to exert more effort. Second, in the closed-loop equilibrium we have a self-deterrence effect: If faction i's effort and stock of destruction are increased, faction $\mathrm{j}$ will exert more effort so that faction i's probability of winning declines. Formally, this effect is reflected by 
$\left[\mathrm{v}+\mathrm{R}\left(\mathrm{s}_{\mathrm{j}}\right)\right] \mathrm{P}_{\mathrm{x}_{\mathrm{j}}}^{\mathrm{i}}[\cdot] \Phi_{\mathrm{s}_{\mathrm{i}}}^{\mathrm{j}}(\cdot)$ in equation $(26) .{ }^{17}$ Compared to the open-loop equilibrium, it

lowers $\lambda_{\mathrm{i}}$ and provides faction $\mathrm{i}$ with the incentive to invest less effort.

We think that the self-deterrence effect is the more interesting effect since, on one hand, it is triggered by the desire to seek revenge and, on the other hand, it reduces (!) the factions' incentive to exert effort in the conflict. In order to investigate the implications of this paradoxical effect, we now calculate explicit solutions for the closedloop equilibrium. In most differential games, analytical closed-loop equilibria are very difficult, if not impossible, to obtain (see, for example, Driskill and McCafferty, 1989, Wirl, 1994; Wirl and Feichtinger, 2002; Jun and Vives, 2004). This is particularly the case since our differential game has two state variables. Nevertheless, a numerical analysis of the closed-loop can provide important information on the implications of the self-deterrence effect.

To see this, we focus on the linear-quadratic model specification already introduced above and use the Hamilton-Jacobi-Bellmann (HJB) approach. Let $\mathrm{V}^{\mathrm{i}}\left(\mathrm{s}_{\mathrm{i}}, \mathrm{s}_{\mathrm{j}}\right)$ be the value function of faction $\mathrm{i}$. This function has to satisfy the HJB equation

\footnotetext{
${ }^{17}$ If the effort of faction $\mathrm{j}$ causes a direct cost of destruction on faction $\mathrm{i}$, the term $-\beta \Phi^{\mathrm{j}}\left(\mathrm{s}_{\mathrm{j}}, \mathrm{s}_{\mathrm{i}}\right)$ additionally enters the Hamiltonian of faction $\mathrm{i}$. The self-deterrence effect then becomes $\left[\left[\mathrm{v}+\mathrm{R}\left(\mathrm{s}_{\mathrm{j}}\right)\right] \mathrm{P}_{\mathrm{x}_{\mathrm{j}}}^{\mathrm{i}}[\cdot]-\beta\right] \Phi_{\mathrm{s}_{\mathrm{i}}}^{\mathrm{j}}(\cdot)$. This shows that with a direct cost of destruction, the self-deterrence effect is larger than without this direct cost. Intuitively, in choosing its effort level today, a faction takes into account that the corresponding increase in the opponent's future effort level not only reduces its winning probability, but also increases the direct cost of destruction suffered. Hence, the incentive to reduce effort today becomes even stronger when we consider the case of $\beta>0$, compared to the case of $\beta=0$.
} 


$$
\begin{aligned}
\mathrm{rV}^{\mathrm{i}}\left(\mathrm{s}_{\mathrm{i}}, \mathrm{s}_{\mathrm{j}}\right)=\max _{\mathrm{x}_{\mathrm{i}}}\{[1 / 2 & \left.+\eta\left[\mathrm{x}_{\mathrm{i}}-\Phi^{\mathrm{j}}\left(\mathrm{s}_{\mathrm{j}}, \mathrm{s}_{\mathrm{i}}\right)\right]\right]\left[\mathrm{v}+\alpha \mathrm{s}_{\mathrm{j}}\right]-\mathrm{c}_{\mathrm{i}} \mathrm{x}_{\mathrm{i}}^{2} / 2 \\
& \left.+\mathrm{V}_{\mathrm{i}}^{\mathrm{i}}\left(\mathrm{s}_{\mathrm{i}}, \mathrm{s}_{\mathrm{j}}\right)\left[\mathrm{x}_{\mathrm{i}}-\delta \mathrm{s}_{\mathrm{i}}\right]+\mathrm{V}_{\mathrm{j}}^{\mathrm{i}}\left(\mathrm{s}_{\mathrm{i}}, \mathrm{s}_{\mathrm{j}}\right)\left[\Phi^{\mathrm{j}}\left(\mathrm{s}_{\mathrm{j}}, \mathrm{s}_{\mathrm{i}}\right)-\delta \mathrm{s}_{\mathrm{j}}\right]\right\}
\end{aligned}
$$

for every $\left(\mathrm{s}_{\mathrm{i}}, \mathrm{s}_{\mathrm{j}}\right)$. Carrying out the maximization in (28) gives

$$
\Phi^{\mathrm{i}}\left(\mathrm{s}_{\mathrm{i}}, \mathrm{s}_{\mathrm{j}}\right)=\mathrm{x}_{\mathrm{i}}=\frac{\eta\left(\mathrm{v}+\alpha \mathrm{s}_{\mathrm{j}}\right)+\mathrm{V}_{\mathrm{i}}^{\mathrm{i}}\left(\mathrm{s}_{\mathrm{i}}, \mathrm{s}_{\mathrm{j}}\right)}{\mathrm{c}_{\mathrm{i}}}
$$

Inserting (29) back into (28) yields

$$
\begin{aligned}
r^{i}\left(s_{i}, s_{j}\right)=[1 / 2 & \left.+\eta\left[\Phi^{i}\left(s_{i}, s_{j}\right)-\Phi^{j}\left(s_{j}, s_{i}\right)\right]\right]\left[v+\alpha s_{j}\right]-c_{i}\left[\Phi^{i}\left(s_{i}, s_{j}\right)\right]^{2} / 2 \\
& +V_{i}^{i}\left(s_{i}, s_{j}\right)\left[\Phi^{i}\left(s_{i}, s_{j}\right)-\delta s_{i}\right]+V_{j}^{i}\left(s_{i}, s_{j}\right)\left[\Phi^{j}\left(s_{j}, s_{i}\right)-\delta s_{j}\right] .
\end{aligned}
$$

This is a partial differential equation for the value function $V^{i}$. For the sake of tractability, we focus on the symmetric case with $c_{i}=c$ and $s_{i 0}=s_{0}$. As a solution of (30), we try the linear-quadratic value function

$$
\mathrm{V}^{\mathrm{i}}\left(\mathrm{s}_{\mathrm{i}}, \mathrm{s}_{\mathrm{j}}\right)=\mathrm{z}_{0}+\mathrm{z}_{1} \mathrm{~s}_{\mathrm{i}}+\mathrm{z}_{2} \mathrm{~s}_{\mathrm{i}}^{2}+\mathrm{z}_{3} \mathrm{~s}_{\mathrm{j}}+\mathrm{z}_{4} \mathrm{~s}_{\mathrm{j}}^{2}+\mathrm{z}_{5} \mathrm{~s}_{\mathrm{i}} \mathrm{s}_{\mathrm{j}}
$$

The z's are constants that have to be determined such that the value function (31) satisfies the HJB equation (30). Note that the z's are the same for both players because we focus on symmetric players. Using equation (31) in (29), the effort level of faction $i$ in the closed-loop equilibrium can be written as

$$
\Phi^{\mathrm{i}}\left(\mathrm{s}_{\mathrm{i}}, \mathrm{s}_{\mathrm{j}}\right)=\frac{\eta \mathrm{v}+\mathrm{z}_{1}}{\mathrm{c}}+\frac{2 \mathrm{z}_{2}}{\mathrm{c}} \mathrm{s}_{\mathrm{i}}+\frac{\eta \alpha+\mathrm{z}_{5}}{\mathrm{c}} \mathrm{s}_{\mathrm{j}}
$$

Inserting this expression and the assumption of a symmetric equilibrium $\left(s_{i}=s_{j}=: \hat{s}\right)$ into the law of motion in (8) gives 


$$
\dot{\hat{\mathrm{s}}}=\frac{\eta \mathrm{v}+\mathrm{z}_{1}}{\mathrm{c}}+\left(\frac{\eta \alpha+2 \mathrm{z}_{2}+\mathrm{z}_{5}}{\mathrm{c}}-\delta\right) \hat{\mathrm{s}} .
$$

Equation (33) is an ordinary differential equation determining the dynamics of the (common) stock of destruction. The dynamics lead to a stable and positive steady-state level of destruction if and only if

$$
\frac{\eta v+z_{1}}{\mathrm{c}}>0, \quad \frac{\eta \alpha+2 \mathrm{z}_{2}+\mathrm{z}_{5}}{\mathrm{c}}-\delta<0 .
$$

The next proposition identifies model specifications for which such stable steady states exist and compares it with the open-loop equilibrium and the equilibrium when the factions do not have the desire to exact revenge.

Proposition 4: Suppose factions in a conflict are motivated by the desire to seek revenge and use closed-loop strategies. Then there exists model specifications for which the closed-loop equilibrium attains a stable steady state, even if the open-loop equilibrium does not. More importantly, the effort levels of the factions in the steady state of the closed-loop equilibrium may be lower than the effort levels in the case without revenge. Proof: We first have to determine those values of $\left(z_{0}, z_{1}, z_{2}, z_{3}, z_{4}, z_{5}\right)$ that ensure that (31) satisfies the HJB equation (30). Using (31) and (32) in (30) and sorting terms gives

$$
\mathrm{k}_{0}+\mathrm{k}_{1} \mathrm{~s}_{\mathrm{i}}+\mathrm{k}_{2} \mathrm{~s}_{\mathrm{i}}^{2}+\mathrm{k}_{3} \mathrm{~s}_{\mathrm{j}}+\mathrm{k}_{4} \mathrm{~s}_{\mathrm{j}}^{2}+\mathrm{k}_{5} \mathrm{~s}_{\mathrm{i}} \mathrm{s}_{\mathrm{j}}=0
$$

with

$$
\begin{aligned}
& \mathrm{k}_{0}=\mathrm{rz}_{0}-\frac{\mathrm{v}}{2}+\frac{\left(\eta \mathrm{v}+\mathrm{z}_{1}\right)\left(\eta \mathrm{v}-\mathrm{z}_{1}-2 \mathrm{z}_{3}\right)}{2 \mathrm{c}} \\
& \mathrm{k}_{1}=\mathrm{rz}_{1}-\frac{\eta \mathrm{v}\left(2 \mathrm{z}_{2}-\eta \alpha\right)}{\mathrm{c}}-\frac{\mathrm{z}_{1} \mathrm{z}_{5}}{\mathrm{c}}-\frac{\left(\eta \alpha+\mathrm{z}_{5}\right) \mathrm{z}_{3}}{\mathrm{c}}-\frac{\mathrm{z}_{1}\left(2 \mathrm{z}_{2}-\delta\right)}{\mathrm{c}}
\end{aligned}
$$




$$
\begin{aligned}
& \mathrm{k}_{2}=\mathrm{rz}_{2}-\frac{2 \mathrm{z}_{2}^{2}}{\mathrm{c}}+\frac{2 \mathrm{z}_{2} \delta}{\mathrm{c}}-\frac{\left(\eta \alpha+\mathrm{z}_{5}\right) \mathrm{z}_{5}}{\mathrm{c}} \\
& \mathrm{k}_{3}=\mathrm{rz}_{3}-\frac{\alpha}{2}+\frac{2 \eta \mathrm{vz}}{\mathrm{c}}-\frac{\left(\eta \mathrm{v}+\mathrm{z}_{1}\right)\left(\mathrm{z}_{5}+2 \mathrm{z}_{4}\right)}{\mathrm{c}}-\frac{\left(2 \mathrm{z}_{2}-\delta\right) \mathrm{z}_{3}}{\mathrm{c}} \\
& \mathrm{k}_{4}=\mathrm{rz}_{4}+\frac{2 \eta \alpha \mathrm{z}_{2}}{\mathrm{c}}-\frac{\left(\eta \alpha+\mathrm{z}_{5}\right)^{2}}{2 \mathrm{c}}-\frac{2 \mathrm{z}_{4}\left(2 \mathrm{z}_{2}-\delta\right)}{\mathrm{c}} \\
& \mathrm{k}_{5}=\mathrm{rz}_{5}-\frac{2 \eta \alpha \mathrm{z}_{2}}{\mathrm{c}}+\frac{\left(\eta \alpha+\mathrm{z}_{5}\right)\left(\eta \alpha-2 \mathrm{z}_{4}\right)}{\mathrm{c}}-\frac{2 \mathrm{z}_{5}\left(2 \mathrm{z}_{2}-\delta\right)}{\mathrm{c}}
\end{aligned}
$$

The HJB equation in (35) is satisfied if and only if $\mathrm{k}_{0}=\mathrm{k}_{1}=\mathrm{k}_{2}=\mathrm{k}_{3}=\mathrm{k}_{4}=\mathrm{k}_{5}=0$ (note that the HJB equation has to be satisfied for all $\left.\left(\mathrm{s}_{\mathrm{i}}, \mathrm{s}_{\mathrm{j}}\right)\right)$. This is a system of six ordinary equations in the six unknowns $z_{0}, z_{1}, z_{2}, z_{3}, z_{4}$ and $z_{5}$. As already mentioned above, an analytical solution is not possible. Hence, we demonstrate the proposition by way of an example. Set $\alpha=200, c=100, r=0.05, v=500, \delta=0.3$ and $\eta=1$. Note that for this parameter constellation we obtain $\delta c-\eta \alpha=-170$ so that the open-loop equilibrium does not attain a steady state according to Proposition 1 . In the case without revenge, the above parameter constellation implies a steady state effort level $\widetilde{\mathrm{x}}^{\infty}=5$ and a steady state stock of destruction $\widetilde{\mathrm{S}}^{\infty}=16.667$. In the closed-loop case, the system of equations $\mathrm{k}_{0}=\mathrm{k}_{1}=\mathrm{k}_{2}=\mathrm{k}_{3}=\mathrm{k}_{4}=\mathrm{k}_{5}=0$ is satisfied by six different sets of values of $\left(z_{0}, z_{1}, z_{2}, z_{3}, z_{4}, z_{5}\right)$ implying that there are six closed-loop equilibria. ${ }^{18}$ These combinations are listed in the following table:

\footnotetext{
${ }^{18}$ The multiplicity of closed-loop equilibria in differential games is well known (e.g., Dockner et al, 2000)
} 


\begin{tabular}{|l|r|r|r|r|r|r|}
\hline & \multicolumn{1}{c|}{$\mathbf{z}_{\mathbf{0}}$} & \multicolumn{1}{c|}{$\mathbf{z}_{\mathbf{1}}$} & \multicolumn{1}{c|}{$\mathbf{z}_{\mathbf{2}}$} & \multicolumn{1}{c|}{$\mathbf{z}_{\mathbf{3}}$} & \multicolumn{1}{c|}{$\mathbf{z}_{\mathbf{4}}$} & \multicolumn{1}{c|}{$\mathbf{z}_{\mathbf{5}}$} \\
\hline solution 1 & -83483.6 & -486.7 & 2.8 & -32846.6 & 200.0 & -200.0 \\
\hline solution 2 & 8982.1 & -977.1 & 71.1 & 696.8 & 77.6 & -83.2 \\
\hline solution 3 & 10993.0 & -1240.4 & 63.3 & 829.7 & 57.7 & -51.5 \\
\hline solution 4 & 93029.6 & -493.9 & 1.4 & 72955.4 & 14287.1 & -200.0 \\
\hline solution 5 & 233621.0 & 255.5 & -65.4 & 1635.3 & 131.0 & -67.1 \\
\hline solution 6 & $7.1576 \times 10^{7}$ & -13948.8 & -64.8 & -19384.5 & 132.4 & -64.8 \\
\hline
\end{tabular}

Table 1: Closed-loop equilibria $(\alpha=200, \mathrm{c}=100, \mathrm{r}=0.05, \mathrm{v}=500, \delta=0.3, \eta=1)$

For each of these solutions we can check the stability conditions given by equation (34) and compute the factions' effort levels $(\hat{\mathrm{x}})$ and stocks of destruction $(\hat{\mathrm{s}})$ in the (possible) steady state. This is done in the following table.

\begin{tabular}{|c|r|r|r|r|r|r|}
\hline & $\begin{array}{c}\text { solution } \\
\mathbf{1}\end{array}$ & $\begin{array}{c}\text { solution } \\
\mathbf{2}\end{array}$ & $\begin{array}{c}\text { solution } \\
\mathbf{3}\end{array}$ & $\begin{array}{c}\text { solution } \\
\mathbf{4}\end{array}$ & $\begin{array}{c}\text { solution } \\
\mathbf{5}\end{array}$ & $\begin{array}{c}\text { solution } \\
\mathbf{6}\end{array}$ \\
\hline$\frac{\eta \alpha+2 \mathrm{z}_{2}+\mathrm{z}_{5}}{\mathrm{c}}-\delta$ & -0.244 & 2.290 & 2.450 & -0.272 & -0.279 & -0.244 \\
\hline$\frac{\eta \mathrm{v}+\mathrm{z}_{1}}{\mathrm{c}}$ & 0.133 & -4.771 & -7.404 & 0.061 & 7.555 & -134.488 \\
\hline$\hat{\mathrm{s}}$ & 0.544 & 2.083 & 3.022 & 0.223 & 27.075 & -551.182 \\
\hline$\hat{\mathrm{x}}$ & 0.163 & 0.625 & 0.907 & 0.067 & 8.122 & -165.355 \\
\hline
\end{tabular}

Table 2: Steady state of the closed-loop equilibria $(\mathrm{a}=200, \mathrm{c}=100, \mathrm{r}=0.05, \mathrm{v}=500$, $\delta=0.3, \eta=1)$

Solution 6 can be ruled out since it implies negative effort levels (not only in the steady state, but for every period t). Under solutions $1-5$, in contrast, the closed-loop equilibrium attains a steady state with positive effort levels. Three of these solutions imply a stable steady state (solutions 1,4 and 5). This proves the first part of the proposition. Moreover, under solutions 1 and 4 the steady state effort level is smaller than 
the effort level in the conflict without the desire for revenge $\left(\hat{\mathrm{x}}=0.163<5=\widetilde{\mathrm{x}}^{\infty}\right.$ and $\left.\hat{\mathrm{x}}=0.067<5=\widetilde{\mathrm{x}}^{\infty}\right) . \quad$ (Q.E.D.)

The rationale behind Proposition 3 goes back to the self-deterrence effect of revenge. Even if the condition for a steady state of the open-loop equilibrium identified in Proposition 1 is violated, the self-deterrence effect of revenge may induce the factions to reduce their effort levels such that the closed-loop solution attains a stable steady state with relatively low effort. Moreover, the self-deterrence effect may even be so strong that the intensity of the conflict (measured by the factions' effort levels) is lower than in a conflict where the factions do not have a desire to seek revenge.

The presence of a desire for revenge need not lead to an escalating conflict. On the contrary, as every faction anticipates that the other faction will retaliate tomorrow upon an increase in effort today, the factions ceteris paribus have an incentive to reduce effort today, and this incentive may be so strong that effort is lower than in the case without revenge. Herein lies our first paradox of revenge. As already mentioned in the introduction, this line of reasoning may explain why some real-world conflicts do not escalate even though it is quite obvious that the factions have the desire to exact revenge.

\section{Discussion of results}

Our paradox of revenge result can be given an evolutionary interpretation in the sense that revenge may have evolved as way of achieving socially desirable outcomes. This point is made by Frank (1988). To be sure, revenge, being a commitment device, 
can improve a player's payoff (Schelling, 1960; Crawford, 1982). ${ }^{19}$ Of course, whether we believe that the paradox of revenge result explains what we observe in the real world hinges on whether we think warring factions use closed-loop strategies or open-loop strategies. While the testability of this result is not easy, it depends on the extent to which revenge, being an emotional response, can lead people to ignore the fact that their opponent will retaliate in future. It would appear that the real world may have a mix of both. That is, some conflicts involve open-loop strategies while others involve closedloop strategies. The Hatfield-McCoy feud discussed by Frank (1988) seems to be a good example for the open-loop case. ${ }^{20}$ The conflict of Protestants and Catholics in Ireland and the Cold War mentioned in the introduction are examples where factions seem to use closed-loop strategies.

Our argument that the paradox of revenge result is socially desirable is a normative one. Yet, in establishing this result we only focused on the costs of the conflict to the factions and not its benefits. In particular, we did not include the factions' value from exacting revenge in our social welfare evaluation. This is a tricky issue which is akin to the problem of doing welfare economics in behavioral economics (Carmichael and MacLeod, 2007; Bernheim and Rangel, 2005, 2008). We take the view that including the factions' benefit from revenge in any social welfare calculus will be tantamount to arguing that that the factions in our conflict have masochistic preferences. This is not the case. Neither faction derives satisfaction from suffering destruction. Such destruction is

\footnotetext{
${ }^{19}$ The idea that emotion-based punishment is credible and can improve welfare has been experimentally confirmed by Fehr and Gachter (2000).

${ }^{20}$ Commenting on the bloody feud between the McCoys and Hartfield mentioned in section 1, Frank (1988, p. 2) noted that "[A]t each juncture, it was clear that to retaliate would produce still another round of bloodshed. Yet for almost four decades they persisted."
} 
clearly a cost to them. However, given that destruction has been suffered in the past, the victim derives satisfaction from exacting revenge. Having a preference for revenge is like having intransitive or inconsistent preferences where an action which was a cost in period $t$ becomes a benefit in period $t+1$. Arguably, there are other ways of doing welfare economics when agents have intransitive preferences, although a general consensus is yet to emerge on this issue (see, for example, Carmichael and MacLeod, 2007; Bernheim and Rangel, 2005, 2008). A reader who objects to our interpretation could simply see our paradox of revenge result as a positive result instead of a normative result. That is, the desire for exacting revenge could paradoxically lead to a smaller aggregate cost of conflict.

Proposition 2 shows that a conflict between two militarily unequal factions could be more destructive than a conflict involving equally strong factions. The desire to exact revenge accounts for this counter-intuitive result. A weaker faction with no desire to exact revenge will not put up a fierce fight if he suffers significant destruction from a very strong opponent. However, if the weaker faction derives satisfaction from exacting revenge, then the significant destruction will cause him to exert even more effort which will, in turn, lead the stronger faction to inflict more destruction on him resulting in a vicious circle of actions and counteractions. The history of conflicts is replete with examples where a weaker faction has put up a strong resistance against a much stronger opponent as in the on-going USA invasion of Iraqi and in the Israeli-Palestinian conflict. The desire to exact revenge may account for the determination and resolve of the weaker 
faction in these conflicts. ${ }^{21}$

An interesting implication of proposition 3 is that historical narratives of the atrocities of one group against another, while useful as a way of understanding the past, may also have the undesirable effect of increasing the cost of conflict because they reduce the rate at which past destruction is forgotten. This is especially true between groups with a history of conflict such as the Israelis and Palestinians, the Serbs and Croats, and the Hutus and Tutsis. In contrast, reconstruction assistance such as those given to Lebanon after the 1975-1990 war may help in increasing the rate at which past destruction is forgotten, although memories of the destruction of human lives is unlikely to be affected by such reconstruction assistance.

Indeed, historical narratives of past atrocities do not only reduce $\delta$ but might also increase $\alpha$ (i.e., the benefit from exacting revenge). Such stories may be distorted in order to promote hatred towards one's opponents. Glaeser (2005) presents a non-conflict model

\footnotetext{
${ }^{21}$ From equation (12), aggregate effort, when there is $n o$ desire for revenge, is $\eta v\left(c_{1}+c_{2}\right) / c_{1} c_{2}$. Hence, with no desire for revenge and holding $c_{1}+c_{2}$ fixed, aggregate effort is also higher, the more unequal are the factions. However, this result arises because our contest success function yields strictly-dominant strategies for the factions. It is not driven by the kind of effects discussed above since it is obvious, from equation (12), that $\partial \widetilde{x}_{\mathbf{i}} / \partial \mathrm{c}_{\mathrm{j}}=0$ for $\mathrm{i} \neq \mathrm{j}, \mathrm{i}=1,2$. If we use a different contest success function (say the Tullock function) and there is no desire for revenge, then the weaker faction would reduce his effort as the unit effort cost of the stronger faction decreases, even if the weaker faction's cost remains unchanged. This will lead to a fall in aggregate efforts (see, for example, Amegashie and Kutsoati, 2007). In contrast when there is a desire for revenge, the weaker faction need not reduce his effort when the unit effort cost of the stronger faction falls because the stronger faction's higher effort will increase his accumulated destruction inflicted on the weaker faction which will increase his valuation (i.e., the weaker faction's valuation from exacting revenge). This is the rationale behind the result in the latter part of proposition 3 . This result is not driven by our linear contest success function. While using the Tullock function significantly complicates the analysis (e.g., the open-loop case requires the solution to a two-dimensional system of non-linear differential equations), our general argument is that the desire to exact revenge could cause a weaker faction to increase his effort in response to an increase in effort by a stronger faction.
} 
of such "entrepreneurs of hate" or hate-mongering. He argues that policies intended to promote integration including inter-marriages will tend to make such stories ineffective since these forms of interaction make it easier to verify the truth. However, there is no incomplete information in our model, so stories about past atrocities need not be distorted. However, their continual repetition across generations with the goal of promoting hatred is enough to maintain or increase the utility from exacting revenge or decrease the rate at which past destruction is forgotten.

In repeated games, it is well known that socially desirable or co-operative outcomes can be sustained by using punishments such as trigger (grim) strategies. However, some of these forms of punishment that support co-operation are not immune to renegotiation and so are not credible. Following Farrell and Maskin (1989) and Bernheim and Ray (1989), there is now a literature which focuses on renegotiation-proof equilibria in repeated games. Renegotiation-proofness is an equilibrium refinement that usually narrows the set of subgame-perfect equilibria in a dynamic game. It is interesting to note that since revenge is part of a player's preferences (i.e., he derives utility from exacting revenge), it is a credible threat and so punishing one's opponent is not a Pareto-dominated action. It follows that our paradox of revenge result is not only socially desirable but also renegotiation-proof. A revenge-induced equilibrium is not robust to renegotiation only if the preferences of the players can be changed. It may well be that if mediators appeal to the conscience of warring factions and encourage them to lay down their arms, they may well be trying to moderate their desire for revenge, so that the players would look to the future instead of the past. 


\subsection{Explaining Jaeger and Paserman (2007) result}

In an interesting study on the second Intifada of the Palestinian-Israeli using data on fatalities from September 2000 to January 2005, Jaeger and Paserman (2007) found that Israeli violence does not seem to result in a predictable counter response from the Palestinians. In contrast, they found that Palestinian violence is a good predictor of Israeli violence.

A reason identified by Jaeger and Paserman (2007) is that when the Israelis strike, they anticipate that the Palestinians will retaliate so they put increased defensive measures like border closings and higher vigilance in place making it difficult for the Palestinians to strike back. ${ }^{22}$ However, after controlling for higher Israeli vigilance after an attack, they still find no effect of Israeli violence on Palestinian attacks. They also use intended attacks by the Palestinians but this does not change their result. The authors also found no deterrence or incapacitation effect or motive for either faction. They conclude that Israeli actions can be explained by a revenge motive but the Palestinian actions cannot be explained by a revenge or deterrence motive.

Based on insights from Schelling (1960), the Jaeger and Paserman (2007) explain their puzzling result by arguing that the Palestinians may optimally follow a random strategy in order to make it difficult for the Israelis to predict when they (i.e., the Palestinians) will strike. This is a very plausible explanation. However, it does not necessarily rule out the possibility that the Palestinians try to exact revenge. It shows that

\footnotetext{
${ }^{22}$ This means that a forward-looking player can respond to the threat of retaliation in two ways: (a) reduce its own destructive effort, or (b) reduce the ability of his opponent to carry out his retaliatory threat. Our closed-loop analysis considered the response in (a).
} 
if, indeed, the Palestinians are also exacting revenge, it will be difficult to empirically detect this motive since they follow a random and unpredictable strategy.

As mentioned by Jaeger and Paserman (2007), they take an empirical route as opposed to solving for a full dynamic and game-theoretic equilibrium of violent behavior based on the revenge, incapacitation, and deterrence motives identified in their paper. We have provided such a dynamic game based on two of such motives (i.e., revenge and deterrence). ${ }^{23}$ We offer an alternative and complementary explanation to Jaeger and Paserman's (2007) explanation. Our explanation does not depend on mixed or random strategies since the equilibria of our game are all in pure strategies.

Since our model endogenizes the magnitude of attacks in conflicts as opposed to the frequency of such attacks, our explanation is more appropriate to Jaeger and Paserman's (2007) result pertaining to the number of fatalities than it is to the incidence of fatalities.

The absence of a deterrence effect found by Jaeger and Paserman (2007) makes our open-loop equilibrium a good starting point. Jaeger and Paserman (2007) found that at 60 days after a fatality, the cumulative impulse response functions for both factions almost attain a steady state. Therefore, we will focus on our steady-state open-loop equilibrium as a good approximation.

It is important to note that in our steady state, efforts can only change if one or more of the exogenous parameters of the model changes. For the sake of argument, suppose there is an increase in the unit effort cost of one faction (i.e., Israel) and a

\footnotetext{
${ }^{23}$ One way to incorporate an incapacitation motive in our model is to write faction i's cost of effort as $\mathrm{C}\left[\mathrm{x}_{\mathrm{i}}(\mathrm{t})\right]=\left(\mathrm{c}_{\mathrm{i}}+\mathrm{s}_{\mathrm{j}}\right) \mathrm{x}_{\mathrm{i}}(\mathrm{t})^{2} / 2$. This means that faction i's unit cost of effort is increasing in the accumulated destruction suffered. Solving this model is extremely complicated in the closed-loop case and in the openloop case requires the solution to a two-dimensional system of complicated non-linear equations.
} 
decrease in the unit effort cost of the other faction (i.e., the Palestinians). As will be shown below, this means that there is an increase in Isreali violence in the steady state.

The corresponding rise in the Palestinian's unit cost of effort is consistent with Jaeger and Paserman's (2007) finding that Israel increases its defensive measures after launching an attack. This increases the cost to the Palestinians of launching a counter attack.

Let Israel be faction 1 and the Palestinians be faction 2. Since Israel is the stronger of the two factions, it follows that $0<\mathrm{c}_{1}<\mathrm{c}_{2}$. We can write the change in the steady-state efforts of each faction as:

$\mathrm{dx}_{1}^{\infty *}=\frac{\partial \mathrm{x}_{1}^{\infty *}}{\partial \mathrm{c}_{1}} \mathrm{dc}_{1}+\frac{\partial \mathrm{x}_{1}^{\infty^{*}}}{\partial \mathrm{c}_{2}} \mathrm{dc}_{2}$

and

$\mathrm{dx}_{2}^{\infty^{*}}=\frac{\partial \mathrm{x}_{2}^{\infty *}}{\partial \mathrm{c}_{2}} \mathrm{dc}_{2}+\frac{\partial \mathrm{x}_{2}^{\infty *}}{\partial \mathrm{c}_{1}} \mathrm{dc}_{1}$

Given our assumptions, it follows that $\mathrm{dc}_{1}<0$ and $\mathrm{dc}_{2}>0$. Presumably, the Israelis increase their level of vigilance if they increase the level of destruction inflicted on the Palestinians. This means that $\mathrm{dc}_{1}$ and $\mathrm{dc}_{2}$ will be correlated. A straightforward and simple way of taking this into account is to assume that $\mathrm{dc}_{1}=-\mathrm{dc}_{2} .{ }^{24}$ Then, $\mathrm{dx}_{1}^{\infty^{*}}=\left(\frac{\partial \mathrm{x}_{1}^{\infty^{*}}}{\partial \mathrm{c}_{1}}-\frac{\partial \mathrm{x}_{1}^{\infty^{*}}}{\partial \mathrm{c}_{2}}\right) \mathrm{dc}_{1}$

This gives

\footnotetext{
${ }^{24} \mathrm{We}$ assume an exogenous increase and decrease in $\mathrm{c}_{2}$ and $\mathrm{c}_{1}$ respectively. To be sure, the defensive measures undertaken by the Israelis are costly. This means this effect should be endogenized. We make this assumption for the sake of simplicity.
} 
$\mathrm{dx}_{1}^{\infty *}=\frac{\eta v \delta^{2}\left(\eta \delta \alpha\left(\mathrm{c}_{1}-\mathrm{c}_{2}\right)+\eta^{2} \alpha^{2}-\delta^{2} \mathrm{c}_{2} \mathrm{c}_{2}\right)}{\left(\eta^{2} \alpha^{2}-\delta^{2} \mathrm{c}_{1} \mathrm{c}_{2}\right)^{2}} \mathrm{dc}_{1}$

Since $\mathrm{c}_{1}<\mathrm{c}_{2}$ and $\eta^{2} \alpha^{2}-\delta^{2} \mathrm{c}_{1} \mathrm{c}_{2}<0$ in the steady state, it follows that $\eta^{2} \alpha^{2}-\delta^{2} \mathrm{c}_{2} \mathrm{c}_{2}<0$.

Therefore, $\mathrm{dx}_{1}^{\infty *}>0$ given $\mathrm{dc}_{1}<0$. This implies that the stronger faction (i.e., Israel) increases its destructive effort.

Similarly,

$\mathrm{dx}_{2}^{\infty *}=-\frac{\eta v \delta^{2}\left(\eta \delta \alpha\left(\mathrm{c}_{2}-\mathrm{c}_{1}\right)+\eta^{2} \alpha^{2}-\delta^{2} \mathrm{c}_{1} \mathrm{c}_{1}\right)}{\left(\eta^{2} \alpha^{2}-\delta^{2} \mathrm{c}_{1} \mathrm{c}_{2}\right)^{2}} \mathrm{dc}_{1}$

Given $\mathrm{c}_{1}<\mathrm{c}_{2}$ and $\eta^{2} \alpha^{2}-\delta^{2} \mathrm{c}_{1} \mathrm{c}_{2}<0$ in the steady state, it is possible that $\eta^{2} \alpha^{2}-\delta^{2} \mathrm{c}_{1} \mathrm{c}_{1}<0$.

Hence, it is possible to have $\eta \delta \alpha\left(c_{2}-c_{1}\right)+\eta^{2} \alpha^{2}-\delta^{2} c_{1} c_{1}=0$. This gives $\mathrm{dx}_{2}^{\infty *}=0$.

Therefore, there is no change in the effort of the weaker faction (i.e., the Palestinians).

Ceteris paribus, an increase in the unit cost of the weaker faction reduces its effort. However, this need not change its steady state effort because the increase in the stronger faction's effort increases the weaker faction's value from exacting revenge. If these two opposing effects offset each other, then there will be no change in the weaker faction's effort. This is the intuition for the result that $\mathrm{dx}_{1}^{\infty^{*}}>0$ could lead to $\mathrm{dx}_{2}^{\infty^{*}}=0$. What makes this result increasing is that it is not possible if there is no desire to exact revenge. In that case, given our assumptions above and using the equations given by (12), would have given $d \widetilde{\mathrm{x}}_{1}>0$ and $d \widetilde{\mathrm{x}}_{2}<0$.

In contrast, notice that a fall in the weaker faction's unit cost leading to a rise in his steady state effort will necessarily result in a rise in the stronger faction's effort given 
that the stronger faction's effort remains unchanged. This is consistent with Jaeger and Peserman's (2007) observation that Israel is sufficiently capable of immediately responding to Palestinian attacks. In other words, the Palestinians, unlike the Israelis, cannot put in place effective counter defensive measures against the Israelis even if they anticipate a counter attack by the Israelis.

Consistent with Jaeger and Paserman's (2007) empirical result, our analysis gives an explanation for why the coefficients of the effect of Israeli violence on actual or intended Palestinian violence may not be significantly different from zero, although a revenge motive for the Palestinians is present. This is our second paradox of revenge in conflicts.

\section{Conclusion}

In this paper, we have investigated the implications of the desire for revenge for the dynamics of conflicts. We modeled revenge as a prize-enhancing phenomenon where the utility from exacting revenge is increasing in the stock of past destruction. Surprisingly, it turned out that revenge, understood in this sense, need not destabilize the conflict, but on the contrary may itself be a reason why the devastating spiral of action and counteraction is broken. We obtained results that offered some insights into the dynamics of real-world conflicts.

In conclusion, we hope that our work has shed some light on our understanding of the effect of revenge on the dynamics of conflict and will lead to further work in this area. For example, an interesting but very challenging extension is to endogenize preferences for revenge. Why are some groups more revenge-driven than others? How 
should welfare economics be undertaken for parties who have a desire for exacting revenge? We leave the analysis of such questions for future research.

\section{References}

Amegashie, J.A., and Kutsoati, E. (2007). (Non)intervention in Intra-State Conflicts. European Journal of Political Economy 23: 754-767.

Axelrod, R. (1984). The Evolution of Cooperation. Basic Books, New York.

Bester, H., and Konrad, K.A. (2005). Easy Targets and the Timing of Conflict. Journal of Theoretical Politics 17: 199-215.

Bernheim, B.D., and Rangel, A. (2005). Behavioral Public Economics: Welfare and Policy Analysis with Fallible Decision-Makers. In Peter Diamond and Hannu Vartianen (eds.), Institutions and Behavioral Economics, forthcoming.

Bernheim, B.D., and Rangel, A. (2008). Beyond Revealed Preference: Choice-Theoretic Foundations for Behavioral Welfare Economics. NBER Working Paper No. 13737.

Bernheim, B.D., and Ray, D. (1989). Collective Dynamic Consistency in Repeated Games. Games and Economic Behavior 1: 295-326.

Binmore, K. (1998). Just Playing: Game Theory and the Social Contract II. MIT Press, Cambridge, MA.

Bloom, S.L. (2001). Reflections on the Desire for Revenge. Journal of Emotional Abuse 2: 61-94.

Carlson, L. J. (1995). A Theory of Escalation and International Conflict. Journal of Conflict Resolution 39: 511-34

Carment, D., and Rowlands, D. (1998). Three's Company: Evaluating Third-Party Intervention in Intrastate Conflict. Journal of Conflict Resolution 42: 572-599.

Carmichael, H., and MacLeod, B. W. (2007). Welfare Economics with Intransitive Revealed Preferences. Journal of Public Economic Theory, forthcoming.

Casari, M., and Luini, L. (2006). Peer Punishment in Teams: Emotional or Strategic Choice? Purdue University Economics Working Papers No. 1188.

Chagnon, N. A. (1988). Life Histories, Blood Revenge, and Warfare in a Tribal Population. Science 239: 985 - 992. 
Chang, Y-M., Potter, J., and Sanders, S. (2007). War and Peace: Third-Party Intervention in Conflict. European Journal of Political Economy, forthcoming.

Che, Y-K., and Gale, I. (2000). Difference-Form Contests and the Robustness of All-Pay Auctions. Games and Economic Behavior 30: 22-43.

Crawford, V. (1982). A Theory of Disagreement in Bargaining. Econometrica 50: 607637

Dockner, E.J., Jorgensen, S., Long, N.V. and Sorger, G. (2000), Differential Games in Economics and Management Science, Cambridge University Press.

Driskill, R.A., and McCafferty, S. (1989). Dynamic Duopoly with Adjustment Costs: A Differential Game Approach. Journal of Economic Theory 49: 324-338.

Elster, J. (1990). Norms of Revenge. Ethics 100: 862-885.

Farrell, J., and Maskin, E. (1989). Renegotiation in Repeated Games.

Games and Economic Behavior 1: 327-360.

Fearon, J. D. (1994). Domestic Political Audiences and the Escalation of International Disputes. American Political Science Review 88: 577-92.

Fehr, E., and Gachter, S. (2000). Cooperation and Punishment in Public Goods Experiments. American Economic Review 90: 980-994.

Frank, R.H. (1988). Passions Within Reason: The Strategic Role of the Emotions. New York : W. W. Norton, 1988

Garfinkel, M. R., and Skarpedas, S. (2000). Conflict without Misperceptions or Incomplete Information: how the Future Matters. Journal of Conflict Resolution 44: 793807.

Glaeser, E.L. (2005). The Political Economy of Hatred. Quarterly Journal of Economics 120: 45-86.

Hausken, K. (2008). Whether to Attack a Terrorist's Resource Stock Today or Tomorrow. Games and Economic Behavior, forthcoming.

Hume, D. (1898). An Enquiry Concerning the Principles of Morals. http://www.anselm.edu/homepage/dbanach/Hume-Enquiry\%20Concerning\%20Morals.htm

Jaeger, D.A., and Paserman, D.M. (2007). The Cycle of Violence? An Empirical Analysis of Fatalities in the Palestinian-Israeli Conflict. American Economic Review, forthcoming.

Juah, T. (2002). Kosovo: War and Revenge. Yale University Press, 2002. 
Jun, B., and Vives, X. (2004). Strategic Incentives in Dynamic Duopoly. Journal of Economic Theory 116: 249-281.

Kahneman, D. and Tversky, A. (1979). Prospect Theory: An Analysis of Decision under Risk. Econometrica 47, 263-291.

Kim, S.H., and Smith, R.H. (1993). Revenge and Conflict Escalation. Negotiation Journal 9: 37-43.

Konrad, K.A., and Kovenock, D. (2005). Equilibrium and Efficiency in the Tug-of-War. CEPR Discussion Paper No. 5205.

Knutson, B. (2004). Sweet Revenge? Science 305: 1246 - 1247.

Martinez-Coll, J. and Hirshleifer, J. (1991). The Limits of Reciprocity. Rationality and Society 3: 35-64.

McAfee, R.P., Mialon, H., and Mialon, S. (2007). Do Sunk Costs Matter? Economic Inquiry, forthcoming.

Nalebuff, B (1986). Brinkmanship and Nuclear Deterrence: the Neutrality of Escalation. Conflict Management and Peace Science 9: 19-30

Nussbaum, M. (1999). Sex and Social Justice. Oxford University Press.

Orth, U. (2004). Does Perpetrator Punishment Satisfy Victims' Feelings of Revenge? Aggressive Behavior 30: 62-70.

Rice, O. (1982). The Hatfields and the McCoys. Lexington: University of Kentucky Press.

Romer, P. (2000). Thinking and Feeling. American Economic Review 90: 439-443.

Schelling, T.C. (1960). The Strategy of Conflict. Cambridge, MA: Harvard University Press.

Siqueira, K. (2003). Conflict and Third-Party Intervention. Defence and Peace Economics 14: 389-400.

Skaperdas, S. (1992). Cooperation, Conflict and Power in the Absence of Property Rights. American Economic Review 82: 720-739. 
Stuckless, N., and Goranson, R. (1992). The Vengeance Scale: Development of a Measure of Attitudes toward Revenge. Journal of Social Behavior and Personality 7:2542.

Suny, R. G. (1993). The Revenge of the Past: Nationalism, Revolution, and the Collapse of the Soviet Union. Stanford University Press.

Wirl, F. (1994). The Dynamics of Lobbying - A Differential Game. Public Choice 80: 307-323.

Wirl, F., and Feichtinger, G. (2002). Intrafamiliar Consumption and Saving under Altruism and Wealth Considerations. Economica 26: 93-111. 